\title{
Illusion decrement and transfer of illusion decrement in real- and subjective-contour Poggendorff figures
}

\author{
PETER A. BECKETT \\ Youngstown State University, Youngstown, Ohio
}

\begin{abstract}
The reduction in illusion magnitude with visual inspection and the transfer of such illusion decrement to a noninspected figure were examined in real- and subjective-contour Poggendorff figures. For both types of figures, illusion magnitude decreased significantly, and in a similar manner, during a 5-min inspection period. Postinspection tests showed that inspecting either a real- or subjective-contour figure resulted in a reduction in illusion magnitude for the other, noninspected figure. These findings suggest that real- and subjective-contour Poggendorff figures share a similar global organization and are thus probably processed in a similar manner. These characteristics make subjective-contour figures a useful tool for separating illusion-producing mechanisms into structural and strategy components.
\end{abstract}

Visual geometric illusions have been described by a number of recent investigators (e.g., Coren \& Girgus, 1978; Coren \& Porac, 1984; Coren \& Ward, 1979; Greist-Bousquet \& Schiffman, 1981; Predebon, 1986; Wenderoth \& Wade, 1981) as representing the operation of a number of illusion-producing mechanisms that function at various levels in the processing of visual information. Attempts to estimate the relative contributions of these illusion-producing components have typically involved dividing illusion-producing mechanisms into structural components and cognitive-judgmental, strategy components. Structural components represent factors related to the optics of the eyes, such as blurring (e.g., Coren, 1969), or to contour-induced neural interactions (e.g., Coren, 1970). Strategy components, on the other hand, represent the way higher visual centers interpret visual information (e.g., Coren \& Girgus, 1972a).

Two different experimental techniques have been used to separate these two major classes of effects. One approach (Coren \& Girgus, 1974; Girgus \& Coren, 1973; Girgus, Coren, Durant, \& Porac, 1975) is based on the phenomenon of illusion decrement, the gradual reduction in illusion magnitude that occurs within a few minutes when inspecting an illusion-producing figure using freeeye movements. Illusion decrement is assumed to represent a change in the information-processing strategy used to interpret the figure (see Coren \& Girgus, 1978;

Preparation of this article was made possible in part by faculty development release time granted to the author by Youngstown State University. An earlier version of this work was presented at the meeting of the Eastern Psychological Association, New York, April 1986. I would like to thank Ann Skinner for her help in data analysis. I would also like to thank reviewer Daniel Weintraub and an anonymous reviewer for helpful comments on an earlier draft of this article. Requests for reprints should be sent to Peter A. Beckett, Department of Psychology, Youngstown State University, Youngstown, OH 44555.
Coren, Girgus, \& Schiano, 1986; Girgus \& Coren, 1982, for supporting evidence), and thus the relative contributions of strategy and structural components can be estimated by comparing initial and postinspection illusion magnitudes.

The other experimental approach has been to remove the effects of structural components by using dot (e.g., Coren, 1970; Greist-Bousquet \& Schiffman, 1981; Predebon, 1986; Wenderoth \& Wade, 1981) or subjectivecontour (e.g., Beckett, 1981; Day, Dickinson, \& Jory, 1977; Goldstein \& Weintraub, 1972; Meyer \& Garges, 1979) figures. As Coren and Girgus (1978) have pointed out, the problem with this approach is that, in the process of eliminating structural factors, the stimulus pattern is changed. Thus, the differences in illusion magnitude observed between standard and modified figures may be due to changes in the way the modified figure is processed (i.e., high-level strategy components may be involved) in addition to, or instead of, the elimination of structural effects. In the case of dot figures, the existing research data suggest that such changes in higher-level strategy components are likely to be involved, at least for some subjects. The problem created by the involvement of these higher-level strategy components is that they result in the apparent inconsistency in estimates of the relative contributions of strategy and structural components across experiments. For example, in experiments that used Poggendorff illusion figures, Coren (1970) reported a dot illusion with a magnitude of about $66 \%$ of the line form, whereas Wenderoth and Wade (1981) reported a dot illusion with a magnitude of only $32 \%$ of the corresponding line form. Predebon (1983) has suggested that differences in dot-illusion susceptibility may be the result of the way subjects perceptually organize dot-illusion figures. Predebon (1986) recently tested this position by comparing illusion magnitudes for dot forms of Poggendorff and 
Müller-Lyer figures in a group that was given information about the implied figure in the dot pattern with those in a group that was not given such information. The illusion magnitudes for the informed group were similar to the estimates of Coren (1970), whereas the illusion magnitudes for the uninformed group were consistent with the estimates of Wenderoth and Wade (1981). These findings led Predebon (1986) to argue that "for the contourdeletion technique to provide meaningful estimates of the contribution of cognitive sources of illusory distortions it is necessary to ensure that the dot illusion forms are perceptually organized in the same manner as the linefigure illusions" (p. 489).

The question addressed in the present study was whether the same problem exists when subjective contours are used to remove structural-level components. Coren and Girgus (1978) originally suggested that subjective-contour figures are less likely to evoke different information-processing strategies than are dot figures because subjective-contour figures are more similar in appearance to standard figures. Although this position is reasonable, little direct support for it has been reported to date. The one exception is a previous study by my laboratory that demonstrated that varying the angle of the transversal has similar effects on real- and subjective-contour Poggendorff figures (Beckett, 1981). These results suggested that removing structural factors through the use of subjective contours did not change the operation of higher-level processes. The present study attempted to determine whether real- and subjective-contour Poggendorff figures are perceptually organized in the same manner, and thus likely to evoke similar information-processing strategies. The transferof-illusion-decrement paradigm (Coren \& Girgus, 1974; Porac \& Coren, 1985; Porac, Coren, Girgus, \& Verde, 1979) was used to accomplish this task. This paradigm was first used by Coren and Girgus (1974) with a number of variants of the Müller-Lyer illusion. They found that after observers inspected a standard Müller-Lyer figure for $5 \mathrm{~min}$, the resulting decrement transferred to other noninspected variants of the illusion. Different amounts of transfer were obtained for different variants, with the figures rated as most similar in appearance to the inspected figure showing the greatest amount of transfer. Differences in the amount of transfer based on perceived similarity, rather than on shared structural components, have also been reported by Porac et al. (1979). More recently, Porac and Coren (1985) attempted to determine the basis of the perceived-similarity effect by examining three effects: (1) those of awareness of stimulus differences were examined by varying the color of the illusion figure, (2) those of local features were examined by varying the angles of the wings in a Brentano form of the Müller-Lyer illusion, and (3) those of a globalfeature change were examined by rotating the Brentano form of the Müller-Lyer illusion $180^{\circ}$. Only the global change, which altered the relationship among the stimulus elements, affected the degree to which the inspectioninduced decrement transferred to noninspected figures.
These results led Porac and Coren to conclude that "judgments of close figural similarity among illusion variants (where decrement transfer effects are the greatest) are based on global organizational principles and not on identity of specific features"' (p. 521). They also argued that these findings "suggest that global organization ... is the guideline for establishing perceptual equivalence among illusions forms" (p. 521).

Based on the evidence cited above, if real- and subjective-contour Poggendorff figures are perceptually equivalent in terms of global organization, then the illusion decrement resulting from inspection of a real-contour Poggendorff figure should transfer to a noninspected, subjective-contour variant. Likewise, if subjects inspect a subjective-contour figure, any resulting illusion decrement should transfer to a noninspected real-contour figure. Testing for such transfer was the main purpose of the present study. The study also had two secondary purposes. First, because no data were available on illusion decrement in subjective-contour Poggendorff figures, the present study was designed to provide such data. Given that illusion decrement is viewed as representing a change in the information-processing strategy used to interpret the illusion-producing figure, if real- and subjectivecontour Poggendorff figures differ only in terms of structural components, then a similar pattern of decrement would be expected for both types of figures. Second, although illusion decrement has been demonstrated using a number of different illusion figures (e.g., Coren \& Girgus, 1972b; Coren \& Hoenig, 1972; Girgus \& Coren, 1982), most of the specifics of the nature of decrement are based solely on the Müller-Lyer illusion. Thus, the present study was also an attempt to provide evidence on the generality of illusion-decrement effects by using the Poggendorff, rather than the Müller-Lyer, illusion.

The logic of the present study is based on the assumption that subjective contours are primarily cognitive effects that originate at higher levels in the visual-processing hierarchy. Thus, it should be pointed out that although this view is accepted by many investigators of subjective contours (see Coren, Porac, \& Theodor, 1986; Parks, 1984; and Pritchard \& Warm, 1983, for recent examples of this position), it is not universal. Some investigators, most notably Becker and Knopp (1978), Ginsburg (1975), and Smith and Over $(1975,1976,1977,1979)$, have argued that subjective contours are based on peripheral, physiological mechanisms. This alternative position is based primarily on the results of studies in which various forms of image filtering were imposed on patterns that resulted in the perception of subject contours (Becker \& Knopp, 1978; Ginsburg, 1975), and on studies that demonstrated that perceptual phenomena such as tilt aftereffects, color-contingent aftereffects, orientation aftereffects, and motion aftereffects could be produced using figures that contained subjective contours in place of real contours (Smith \& Over, 1975, 1976, 1977, 1979). However, major challenges have been directed at the results of both types of studies. 
Tyler (1977) pointed out a number of problems with Ginsburg's (1975) filtering interpretation of Kanizsa's (1955) illusory triangle. Becker and Knopp (1978), who also maintained that Ginsburg's results were inconclusive, used a more rigorous, less controversial methodology and concluded that high-frequency filtering contributed to the formation of the Kanizsa triangle in Ginsburg's study. However, using similar filtering techniques and an inducing figure that was in many ways similar to the Kanizsa triangle, Parks and Pendergrass (1982) failed to show a brightness gradient corresponding to the illusory contour. These results thus indicate that although some physiological analogue of filtering may play a role in subjectivecontour formation under some conditions, such a process is not necessary for the formation of subjective contours.

Smith and Over's $(1975,1976,1977,1979)$ conclusion that similar perceptual results obtained with real- and subjective-contour stimuli indicate that the same underlying neural mechanisms are responsible for both types of contours has been challenged by results reported by Halpern and Warm (1980a, 1980b) and Bradley (1982). Halpern and Warm (1980a, 1980b) compared figural fragmentation in real- and subjective-contour figures, and found differences in the frequency of fragmentation, lack of increased fragmentation for subjective-contour figures by preexposure to real-contour figures (and vice versa), and differences between the figures in the effects of dichoptic viewing on the number of fragmentations. Bradley (1982) showed that when subjective contours were presented dichoptically in differing orientations, they merged to form a new combined form, whereas, under similar conditions, real contours yielded binocular rivalry. Taken together, these results suggest that real and subjective contours are not based on a common neural mechanism. It is therefore of interest to test for similar cognitive mechanisms in real- and subjective-contour illusion figures.

\section{METHOD}

\section{Subjects}

Twenty-eight students, 17 males and 11 females, were recruited from introductory psychology classes. All subjects received extra credit for participating. Half of the subjects were randomly assigned to the real-contour inspection group and half were assigned to the subjective-contour inspection group.

\footnotetext{
Stimuli

The inspection and test figures used are shown in Figure 1. All stimuli were drawn in black on separate sheets of paper and duplicated. The central rectangle in both the real- and subjective-contour figures measured $4 \times 10 \mathrm{~cm}$. The oblique lines formed an angle of $45^{\circ}$ with the central rectangle and extended $3 \mathrm{~cm}$ from the point(s) of intersection. All lines in the figures were $1 \mathrm{~mm}$ wide. The diameter of the large circles used to construct the subjective-contour figures was $11 \mathrm{~mm}$ and the diameter of the small circles was $6 \mathrm{~mm}$. All stimuli were presented on a stimulus holder located on a table directly in front of the subject. The stimulus holder was oriented toward the subject, forming an angle of $12^{\circ}$ with the table top. The subjects were seated for all judgments. Because the subjects' heads were not restrained, viewing distance varied somewhat, with the average viewing distance being approximately $40 \mathrm{~cm}$.
}
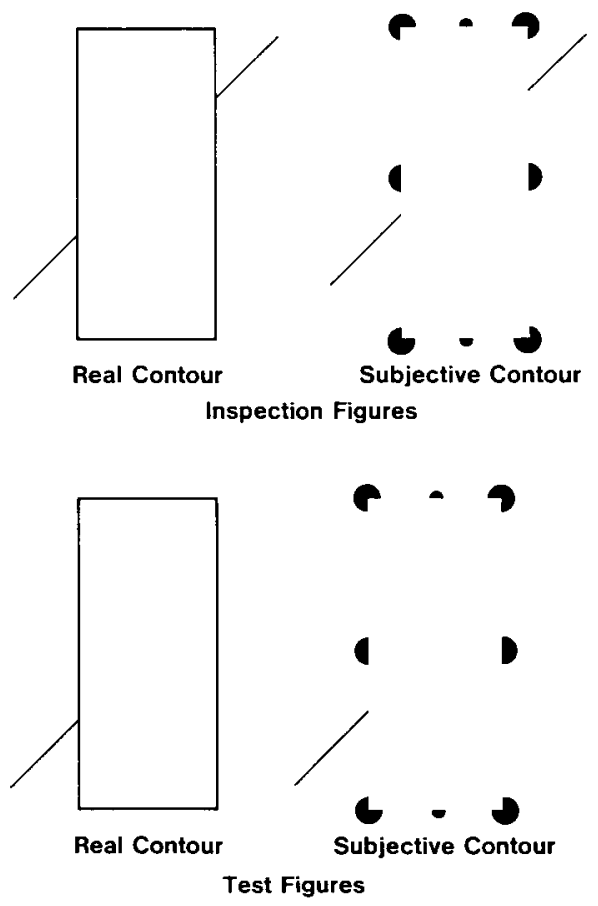

Figure 1. The inspection and test figures used in this study.

\section{Procedure}

During the preinspection test period, all subjects were presented with both the real- and the subjective-contour test figures shown in Figure 1. Subjects were instructed to mark a point on the right side of the central rectangular part of the figure to indicate where they thought the left oblique would appear if it were extended across the figure in the direction in which it was pointing. This illusion measurement technique, in which illusion magnitude is measured as the difference between the subject's mark and the actual point of intersection of the oblique, has also been used by Girgus and Coren $(1987)$ and Pressey and Sweeney $(1969,1970)$. The order in which the two figures were judged was counterbalanced, with half of the subjects in each inspection group judging the subjectivecontour figure first (Order 1) and half judging the real-contour figure first (Order 2). Following these two preinspection judgments, a 5min period of inspecting one type of Poggendorff figure was initiated.

The inspection phase of the experiment was divided into five 1-min inspection periods, each of which was immediately followed by a judgment of the apparent position of the oblique in the type of figure being inspected. During each inspection period, subjects were presented with one of the inspection figures shown in Figure 1, and were instructed to examine the figure carefully by moving their eyes from the oblique line on one side of the figure to the oblique line on the other side. The subjects were observed during each minute of inspection to ensure adherence to the instructions. Half of the subjects were presented with real-contour figures during the inspection phase of the experiment, and half were presented with subjective-contour figures. The two sides of the obliques were objectively aligned in all inspection figures. At the end of each minute of inspection, the inspection figure was removed and a test figure, of the same type as the inspection figure but with only the left half of the oblique present, was presented for judgment. As in the preinspection phase of the experiment, judgments of the test figure were made by having the subject mark a point on the right side of the central rectangular part of the figure. After the subject's judgment of the test figure was completed, an inspection figure was again presented and the subject inspected it for another 1 -min period. At 
the end of the minute, the inspection figure was again replaced with a test figure that the subject marked. This procedure was continued until five inspections and following judgments had been completed.

The inspection phase of the experiment described above was followed by a postinspection test period in which each subject again judged both a real- and a subjective-contour test figure. The procedure and order of judgments for the postinspection tests were the same as those used during the preinspection test period. By the end of the postinspection period, each subject had provided a total of seven judgments of illusion magnitude for the type of figure inspected (one preinspection judgment, one judgment at the end of each minute of inspection, and one postinspection judgment) and two judgments of illusion magnitude (one preinspection judgment and one postinspection judgment) for the other type of figure.

\section{RESULTS}

The mean illusion magnitudes observed for the real- and subjective-contour figures during the preinspection period were calculated separately for the two orders in which the preinspection judgments were made. These data were collapsed over the inspection-figure variable because each order was used by half of the subjects in each inspection condition and the subjects in the two inspection groups were treated alike during the preinspection period. A 2 $\times 2$ (judgment order $\times$ test figure) mixed-design analysis of variance (ANOVA) was performed on these data to examine the possibility that judging the real-contour figure first might have changed the cognitive strategy for judging the subjective-contour figure, or vice versa. Such an effect has been indicated for dot forms of the Poggendorff and Müller-Lyer illusions (Predebon, 1983, 1986). The main effect of the test-figure variable was significant $[F(1,26)=51.66, p<.001]$, with the real-contour figure yielding significantly greater illusion magnitude $(M=$ $14.0)$ than the subjective-contour figure $(M=7.5)$. However, neither the main effect of judgment order $[F(1,26)=.57]$ nor the judgment order $\times$ test figure interaction $[F(1,26)=.16]$ were significant. Thus, there was no indication during the preinspection period that the processing of the figures was affected by the order in which they were judged.

Illusion decrement in the real- and subjective-contour inspection groups was evaluated by comparing the mean illusion magnitudes observed for the figure inspected during the preinspection period and each of the five inspection-test periods. These data, which were collapsed over the judgment-order variable, are presented in Figure 2. The justification for combining the data from the two judgment orders was a preliminary analysis that indicated that the main effect of the preinspection judgment-order variable, and the interactions that involved this variable, were all nonsignificant. A $2 \times 6$ (inspection figure $x$ inspection time) mixed-design ANOVA performed on the data in Figure 2 showed that the realcontour figure yielded significantly larger illusory effects than did the subjective-contour figure $[F(1,26)=5.97$, $p<.025]$, and that, during inspection, illusion magnitude decreased significantly $[F(5,130)=11.02$, $p<.001]$. The interaction was nonsignificant $[F(5,130)$

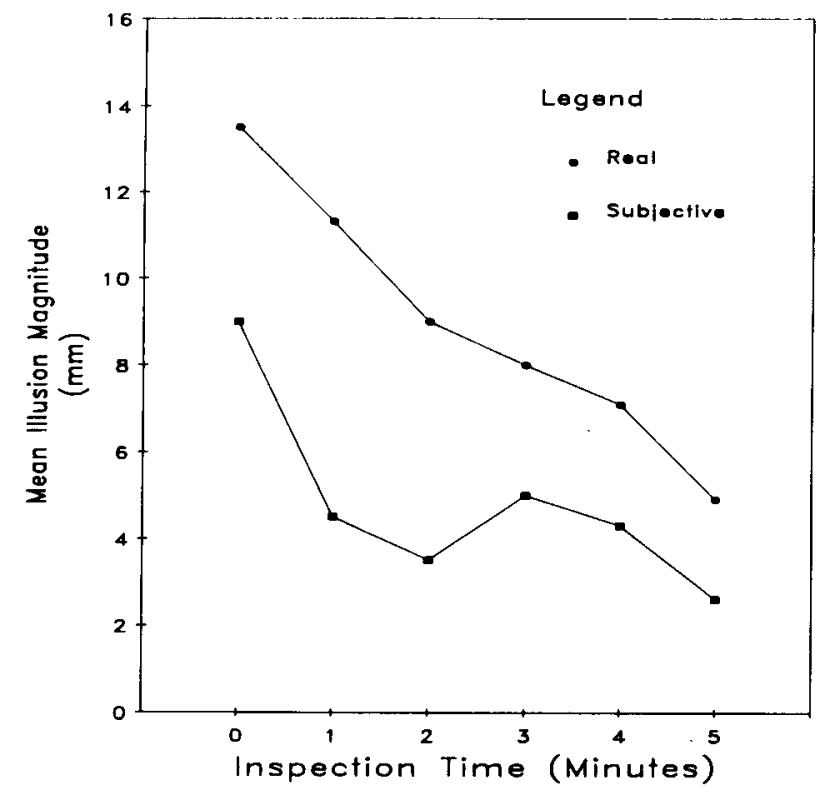

Figure 2. Mean illusion magnitude for real- and subjective-contour Poggendorff figures as a function of inspection time. Inspection Time 0 represents the preinspection test.

$=1.48]$, which indicates that decrement was similar for both figures. The illusion magnitudes observed for each type of figure at each inspection time were also analyzed using two-tailed $t$ tests. All of the observed $t$ values were significant at the .05 level or beyond, which indicates that all of the illusion magnitudes shown in Figure 2 are significantly greater than zero.

The effects of inspection condition on the magnitude of decrement and the transfer of decrement to the noninspected figure were evaluated by comparing pre- and postinspection illusion magnitudes for each figure as a function of inspection condition. Once again, a preliminary analysis yielded no significant effects involving the judgment-order variable; therefore the data for the two judgment orders used in each inspection condition were combined. These data, which are presented in Table 1, were analyzed using a $2 \times 2 \times 2$ (inspection conditions $x$ tests $\times$ type of figure) mixed-design ANOVA. The effect of type of figure, which is now being analyzed as a within-subjects variable, was significant $[F(1,26)=$ $92.37, p<.001]$, with the real-contour figure again yielding larger effects. A significant decrease in illusion magnitude from the pre- to the postinspection periods,

Table 1

Mean Pre- and Postinspection Illusion Magnitudes (in millimeters) for Real- and Subjective-Contour Poggendorff Figures as a Function of Inspection Condition

\begin{tabular}{lccccc}
\hline & \multicolumn{3}{c}{ Inspection Condition } \\
\cline { 2 - 3 } \multicolumn{1}{c}{ Test Figure } & \multicolumn{2}{c}{ Real Contour } & & Subjective Contour \\
\cline { 2 - 3 } \cline { 5 - 6 } & Pretest & Posttest & & Pretest & Posttest \\
\hline Real contour & 13.6 & 8.6 & & 14.5 & 11.4 \\
Subjective contour & 6.1 & 2.6 & & 9.0 & 4.8 \\
\hline
\end{tabular}


which was similar in both inspection conditions and for both figures, was also found (i.e., the main effect of tests was significant $[F(1,26)=25.73, p<.001])$, but the inspection conditions $\times$ tests $[F(1,26)=.13]$, the type of figure $\times$ tests $[F(1,26)=.08]$, and the inspection condition $\times$ tests $\times$ type of figure $[F(1,26)=1.79]$ interactions were not significant. These data thus indicate that inspecting either a real- or a subjective-contour figure not only resulted in pre- to postinspection changes in the figure that was inspected, but also that the resulting decrement transferred to the noninspected figure. The lack of a significant three-factor interaction suggests that transfer was equivalent for both inspection conditions and that the amount of decrement shown by the noninspected figure was not significantly different from the amount shown by the inspected figure. In the real-contour inspection condition, the subjective-contour figure yielded a decrement score that was $70 \%$ of the decrement shown by the realcontour figure, whereas in the subjective-contour inspection condition, the real-contour figure yielded a decrement score that was $74 \%$ of the decrement shown by the subjective-contour figure.

One final aspect of the results worth noting involves a comparison of the illusion magnitudes observed for each figure at the end of inspection (i.e., Exposure Minute 5 in Figure 2) and the corresponding postinspection illusion magnitudes presented in Table 1 . For both the real- and the subjective-contour figures, the posttest values given in Table 1 are larger. To evaluate this apparent increase in illusion magnitude and to determine if it was related to the fact that the illusion magnitudes in Table 1 represent data collapsed over posttest judgment orders, the illusion magnitudes observed at the end of inspection were compared to the magnitudes observed during the postinspection tests as a function of the figure inspected and judgment order used. These data, which are presented in Table 2, were analyzed using a $2 \times 2 \times 2$ (inspection figure $\times$ judgment order $\times$ tests) mixed-design ANOVA. This analysis yielded a significant main effect of judgment order $[F(1,24)=4.49, p<.05]$ and a significant inspection figure $\times$ judgment order interaction $[F(1,24)$ $=4.93, p<.05]$. These effects reflect the fact that, collapsed over the two tests of illusion magnitude, significantly greater illusion magnitudes were obtained for the

Table 2

Mean Illusion Magnitudes (in millimeters) for Real- and Subjective-Contour Poggendorff Figures at the End of Inspection and During Postinspection Testing as a Function of Judgment Order

\begin{tabular}{lccccc}
\hline & \multicolumn{4}{c}{ Test } \\
\cline { 2 - 4 } Inspection Figure & \multicolumn{2}{c}{ End of Inspection } & & \multicolumn{2}{c}{ Postinspection } \\
\cline { 2 - 3 } \cline { 5 - 6 } Order 1 & Order 2 & & Order 1 & Order 2 \\
\hline Real contour & 2.3 & 7.3 & & 5.0 & 12.1 \\
Subjective contur & 3.4 & 3.9 & & 5.1 & 4.4 \\
\hline
\end{tabular}

Note-Order 1 subjects judged the subjective-contour figure first and Order 2 subjects judged the real-contour figure first. real-contour figure when it was judged first (Judgment Order 2), whereas the subjective-contour figure was not affected by judgment order. The main effect of tests $[F(1,24)=12.09, p<.01]$ was also significant, which indicates that the postinspection tests yielded larger illusion magnitudes than were observed during the test at the end of the inspection period. However, none of the interactions involving the tests variable were significant, which indicates that the increase in illusion magnitude from Test 6 to Test 7 was not differentially affected by either the order of postinspection testing or the figure inspected. These results also make individual differences a plausible explanation for the inspection figure $\times$ judgment order interaction. The effect of judgment order on the illusion magnitude of the real-contour figure did not change from Test 6 to Test 7, and during Test 6 subjects in the two judgment-order groups were treated exactly alike.

\section{DISCUSSION}

Porac and Coren (1985) presented data that indicated that "the global form of the configuration must be kept constant if there is to be transfer of illusion decrement among variants"' (p. 521). Based on Porac and Coren's argument, the transfer of illusion decrement from realto subjective-contour figures (and vice versa) found in the present study suggests that real- and subjective-contour figures share a similar global organization. Comparing the present results to those reported by Porac and Coren for the Müller-Lyer illusion, the degree of illusion transfer obtained $(70 \%$ and $74 \%$ for the real- and subjectivecontour inspection conditions, respectively) is closer to the results of their local-feature change experiment (Experiment 2) than to the results of their global-feature change experiment (Experiment 3). In Experiment 2, Porac and Coren found that their "Different" groups, who were tested using a figure with a different wing angle than the angle in the inspection figure, showed an illusiontransfer effect about $95 \%$ of that shown by the "Same" groups. In Experiment 3, Porac and Coren found that the "Different" conditions, in which the orientation of the test figure was different than the orientation of the inspection figure, showed a transfer effect that was only about $19 \%$ of that shown by the "Same" orientation condition.

As noted above, some investigators would argue that real- and subjective-contour figures share common peripheral physiological mechanisms. From this perspective, one might contend that such structural similarities are the basis for both the similar patterns of decrement and the transfer of decrement across figures revealed in the present study. In addition to the problems with a peripheral explanation of subjective-contour formation discussed earlier, two additional findings militate against attributing the present results to structural similarities between the two types of figures. First, in a study using the Müller-Lyer illusion, Coren and Girgus (1974) showed that structural similarity between the inspection and trans- 
fer figures, measured both in terms of the number of missing contour units and in terms of the number of missing pattern elements, did not predict transfer as well as ratings of perceived similarity. Second, Coren et al. (1986) found that continued inspection of a field of parallel lines slanted at the same orientation as the wings of the MüllerLyer illusion figure used during testing yielded no more illusion decrement than did inspecting an array of randomly spaced dots. These findings thus fail to support adaptation or fatigue of cortical receptors as the basis for illusion decrement.

Based on the argument that illusion decrement represents a change in the cognitive, strategy components of an illusion (see Coren \& Girgus, 1978; Girgus \& Coren, 1982; Porac \& Coren, 1985), then the similar pattern of decrement observed in the present study for both real- and subjective-contour figures also suggests that removing structural components through the use of subjective contours does not change the way in which higherorder strategy components operate. Thus, the general illusion-decrement results support the same conclusion as do the transfer-of-decrement results. These findings, together with Beckett's (1981) data showing that varying the angle of the transversal had similar effects on realand subjective-contour Poggendorff figures, suggest that the use of subjective-contour figures to remove structurallevel components is preferential to the use of dot figures because subjective-contour figures are more likely to leave unchanged the manner in which higher-level processing mechanisms operate. The lack of judgment-order effects on the illusion magnitudes observed during the preinspection period also supports this conclusion.

Because almost all previous information on illusion decrement has been based on the Müller-Lyer illusion, it should be noted that the results of the present study are consistent with the results of a number of previous MüllerLyer decrement studies. For example, Coren, Girgus, and their associates (Coren \& Girgus, 1972a; Girgus et al., 1975; Girgus, Coren, \& Horowitz, 1973) have evaluated decrement in a number of variants of the Müller-Lyer illusion, and found similar decrement patterns for standard and modified figures. This finding is consistent with the similar decrement patterns found in real- and subjectivecontour figures in the present study. Also, Coren and Girgus (1974) and Porac et al. (1979) have shown that inspecting one type of figure led to significant pre- to postinspection reductions in illusion magnitude for similar noninspected figures. These results are similar to the transfer of decrement across figures obtained in the present study. Thus, the present study provides muchneeded evidence for the similarity of illusion decrement effects in different illusions.

One final aspect of the present results that deserves a brief comment is the increase in illusion magnitude that occurred between the last judgment of the inspection phase and the final posttest judgment. As previously indicated, this increase did not appear to be related to the order in which the postinspection judgments were made. Are we thus to conclude that illusion-decrement effects are very temporary, with a significant reduction in the effects occurring in the brief time between these last two judgments? Such a result would not be expected from the type of change in cognitive strategy typically offered to explain illusion decrement. Other than the Müller-Lyer decrement study of Girgus et al. (1975), which showed that some of the decrement resulting from inspection was present the next day, there are no data on the time frame for decrement effects, and so a firm conclusion from the present results is not possible. An alternative explanation is that the increase in magnitude observed reflects a fluctuation in illusion magnitude that occurs during the process of subjects trying to correct their inappropriate, illusionproducing strategy for visual processing. In other words, prior to subjects reaching their final, minimum illusionproducing strategy, they may vary the strategy selected to some extent during the course of interacting with the illusion-producing figure. Although this explanation is admittedly speculative, an examination of the data presented in Figure 2 of Coren and Girgus (1972b) reveals a fairly substantial fluctuation in the magnitude of the Poggendorff illusion during the inspection period. Further research examining the time course of decrement effects is obviously needed.

\section{REFERENCES}

Becker, M. F., \& KoPP, J. (1978). Processing of visual illusions in the frequency and spatial domains. Perception \& Psychophysics, 23, 521-526.

Beckett, P. A. (1981, May). Transversal angle effects in real-and subjective-contour Poggendorff figures. Paper presented at the meeting of the Midwestern Psychological Association, Detroit, MI.

BRADLEY, D. R. (1982). Binocular rivalry of real vs. subjective contours. Perception \& Psychophysics, 32, 85-87.

COREN, S. (1969). The influence of optical aberrations on the magnitude of the Poggendorff illusion. Perception \& Psychophysics, 6, 185-186.

COREN, S. (1970). Lateral inhibition and geometric illusions. Quarterly Journal of Experimental Psychology, 22, 274-278.

COREN, S., \& GiRgus, J. S. (1972a). Differentiation and decrement in the Mueller-Lyer illusion. Perception \& Psychophysics, 12, 466-470.

COREN, S., \& Girgus, J. S. (1972b). Illusion decrement in intersecting line figures. Psychonomic Science, 26, 108-110.

COREN, S., \& GiRgus, J. S. (1974). Transfer of illusion decrement as a function of perceived similarity. Journal of Experimental Psychology, 102, 881-887.

COREN, S., GIRGUS, J. S. (1978). Seeing is deceiving: The psychology of visual illusions. Hillsdale, NJ: Erlbaum.

Coren, S., Girgus, J. S., * SChiano, D. (1986). Is adaptation of orientation-specific cortical cells a plausible explanation of illusion decrement? Bulletin of the Psychonomic Society, 24, 207-210.

COREN, S., \& HoENIG, P. (1972). Eye movements and decrement in the Oppel-Kundt illusion. Perception \& Psychophysics, 12, 224-225.

Coren, S., \& Porac, C. (1984). Structural and cognitive components in the Müller-Lyer illusion assessed via Cyclopean presentation. Perception \& Psychophysics, 35, 313-318.

Coren, S., Porac, C., \& Theodor, L. H. (1986). The effects of perceptual set on the shape and apparent depth of subjective contours. Perception \& Psychophysics, 39, 327-333.

COREN, S., \& WARD, L. M. (1979). Levels of processing in visual illu- 
sions: The combination and interaction of distortion-producing mechanisms. Joumal of Experimental Psychology: Human Perception \& Performance, 5, 324-335.

Day, R. H., Dickinson, R. G., Jory, M. K. (1977). The Poggendorff illusion with subjective contours. Quarterly Journal of $E x$ perimental Psychology, 29, 219-226.

GINSBURG, A. P. (1975). Is the illusory triangle physical or imaginary? Nature, 257, 219-220.

GiRgus, J. S., \& Coren, S. (1973). Peripheral and central components in the formation of visual illusions. American Joumal of Optometry \& Archives of the American Optometric Society, 50, 533-540.

Girgus, J. S., \& CoRen, S. (1982). Assimilation and contrast illusions: Differences in plasticity. Perception \& Psychophysics, 32, 555-561.

Girgus, J. S., COREN, S. (1987). The interaction between stimulus variations and age trends in the Poggendorff illusion. Perception \& Psychophysics, 41, 60-66.

Girgus, J. S., Coren, S., Durant, M., \& Porac, C. (1975). The assessment of components involved in illusion formation using a longterm decrement procedure. Perception \& Psychophysics, 18, 144-148.

Girgus, J. S., Coren, S., \& HorowtTz, L. (1973). Peripheral and central components in variants of the Mueller-Lyer illusion. Perception \& Psychophysics, 13, 157-160.

Goldstein, M. B., \& Weintraub, D. J. (1972). The parallel-less Poggendorff: Virtual contours put the illusion down but not out. Perception \& Psychophysics, 11, 353-355.

Greist-Bousquet, S., \& SChiffMan, H. R. (1981). The role of structural components in the Mueller-Lyer illusion. Perception \& Psychophysics, 30, 505-511.

HALPERN, D. F., \& WARM, J. S. (1980a, November). The disappearance of dichoptically presented real and subjective contours. Paper presented at the meeting of the Psychonomic Society, St. Louis, MO.

HAlPERN, D. F., \& WARM, J. S. (1980b). The disappearance of real and subjective contours. Perception \& Psychophysics, 28, 229-235.

KANizsA, G. (1955). Margini quasi-percettivi in campi con stimulazioni omogonea, Rivista di Psicologia, 49, 7-30.

Meyer, G. E., \& Garges, C. (1979). Subjective contours and the Poggendorff illusion. Perception \& Psychophysics, 26, 302-304.

PARKs, T. E. (1984). Illusory figures: A (mostly) atheoretical review. Psychological Bulletin, 95, 282-300.
Parks, T. E., Pendergrass, L. (1982). On the filtered-components approach to illusory visual contours. Perception \& Psychophysics, 32, $491-493$.

PORaC, C., COREN, S. (1985). Transfer of illusion decrement: The effects of global versus local figural variations. Perception \& Psychophysics, 37, 515-522.

Porac, C., Coren, S., Girgus, J. S., \& Verde, M. (1979). Visualgeometric illusions: Unisex phenomena. Perception, 8, 401-412.

Predebon, J. (1983). Recognition processes and occurrence of the dot Poggendorff illusion. Perceptual \& Motor Skills, 56, 471-474.

Predebon, J. (1986). The effect of line-figure information on the magnitude of the dot forms of the Poggendorff and Müller-Lyer illusion. Perception, 15, 483-490.

Pressey, A. W., SWeEney, O. (1969). A variation of the Poggendorff illusion. Perceptual \& Motor Skills, 28, 883-886.

Pressey, A. W., \& Sweeney, O. (1970). Age changes in the Poggendorff illusion as measured by the method of production. Psychonomic Science, 19, 99-100.

Pritchard, W. S., W Warm, J. S. (1983). Attentional processing and the subjective contour illusion. Journal of Experimental Psychology: General, 112, 145-175.

SMITH, A. T., \& OvER, R. (1975). Tilt aftereffects with subjective contours. Nature, 257, 581-582.

Smith, A. T., \& Over, R. (1976). Color-selective tilt aftereffects with subjective contours. Perception \& Psychophysics, 20, 305-308.

Smith, A. T., \& Over, R. (1977). Orientation masking and the tilt illusion with subjective contours. Perception, 6, 441-447.

Smith, A. T., \& OVER, R. (1979). Motion aftereffect with subjective contours. Perception \& Psychophysics, 25, 95-98.

TYLER, C. W. (1977). Is the illusory triangle physical or imaginary? Perception, 6, 603-604.

WENDEROTh, P., \&ADE, N. (1981). An investigation of line and dot forms of the Müller-Lyer and Poggendorff illusions. Quarterly Journal of Experimental Psychology, 33, 77-85.

(Manuscript received August 14, 1987; revision accepted for publication November 10, 1988.) 